\title{
The prevalence of asthma among children in South Africa is increasing - is the need for medication increasing as well? A case study in the Vaal Triangle
}

\author{
Maria A Oosthuizen ${ }^{1 *}$, Antony J Mundackal ${ }^{1,2}$ and Caradee $Y$ Wright $^{1}$ \\ ${ }^{1}$ Council for Scientific and Industrial Research (CSIR), Climate Studies, Modelling and Environmental \\ Health Research Group, P O Box 395, Pretoria, 0001, South Africa. \\ ${ }^{2}$ School of Health Systems and Public Health, University of Pretoria, South Africa. \\ * Corresponding author: CSIR NRE, PO Box 395, Pretoria, 0001, Email: roosthui@csir.co.za,
} Tel: 0128412035.

\begin{abstract}
Asthma, a chronic inflammatory condition of the airways, is a global public health concern. In southern Africa the prevalence of asthma has increased over the last few decades. In the current study, all 10-year-old learners from three of the schools (one each in Sasolburg, Vanderbijlpark and Vereeniging) that participated in the 1990 Vaal Triangle Air Pollution and Health Study, were selected as the study population for a cross-sectional study conducted in 2010. Both the 1990 and 2010 studies investigated several exposure factors but focussed on respiratory illnesses as main health outcomes. Although the overall ethnicity profile in 2010 was different from that of 1990, the socioeconomic status of the study populations were very similar - the reason being that the same schools were used and the participating children were from the same immediate environment. The results of the 2010 study were then compared to the results of all 10-year-olds, from the same three schools, who participated in the 1990 study. The results showed the difference in prevalence of asthma during the two study years was statistically significant. The difference in the percentage of children who had ever been diagnosed with asthma and were reportedly on medication in 1990 and 2010 was, however, not statistically significant, indicating that although the prevalence of asthma increased, the demand for medication to control the condition may not have increased as well.
\end{abstract}

Keywords: Asthma, prevalence, children, South Africa, Vaal Triangle, medication, VAPS, 1990 and 2010.

\section{Background}

Asthma, a public health concern both globally and in South Africa, is, also a chronic disease in children (To et al., 2012). This disease has an adverse impact on quality of life, resulting in an added burden on health care service delivery (To et al., 2012), which in turn has financial implications. Asthma can be defined as "a chronic inflammatory condition of the airways, which is usually allergic in origin and characterised by hyper-responsive airways that constrict easily in response to stimuli" (Lalloo et. al., 2000). A number of epidemiological studies have identified possible risk factors for asthma. Exposures to indoor air pollutants (Desalu et al., 2009; Oosthuizen, 2004; Mishra, 2003 ,) the existing status of health and well-being as characterised by allergic reactions (Green, 2011; Desalu et al, 2009; Oosthuizen, 2004; Kurukulaaratchy, et. al. 2003), as well as lifestyle traits such as 'ever smoking' (Desalu et al, 2009; Oosthuizen, 2004; Mishra, 2003) and being overweight (Desalu et al., 2009; Chinn, 2003; Aaron et al., 2004; Oosthuizen, 2004) are some examples. Urbanisation is another risk factor for asthma identified as such through various studies, including studies from South Africa (To et al. 2012; Green, 2011). A review on the prevalence of asthma in children in southern Africa concluded that "the prevalence of asthma in Southern Africa is high and has increased in all populations over the last few decades" (Green, 2011). An aspect that has, however, not been studied as comprehensively as the prevalence of asthma in South Africa, is whether there has also been an increase in the need for medication to control the asthma.

\section{Methods}

In 1990, the Vaal Triangle Air Pollution Health Study or VAPS, a comprehensive epidemiological study in the Vaal Triangle, South Africa, investigated the upper and lower respiratory health status of aged eight to 14 year-old schoolchildren attending different schools (Terblanche, 1998). The study, supported by Government and industries, was the result of concerns expressed by the public about the levels of air pollution and the respiratory health status of children in the Vaal Triangle. This area has since been declared an air pollution priority area, which is an indication that air pollution levels in the area are exceeding health standards. For the purpose of the current study (conducted in 2010) three of the schools that participated in the 1990 study were sampled and the respiratory health status of the 10year olds in these schools determined. These results were then compared to that of the 1990 VAPS study, using the original questionnaire data collected from 10 -year olds attending the same schools. Both studies investigated upper and lower respiratory illnesses, with a focus on the prevalence of these illnesses. Although the overall ethnicity profile in 2010 was different from that of 1990 , the socio-economic status of the study populations were very similar - the reason being that the same schools were used in both studies and that the participating children were from the same immediate environment. The results of the study were published in a Masters dissertation (Mundackal, 2014) with more publications being envisaged. Asthma was among the illnesses for which the prevalence was determined. In addition, information available from both studies included whether the asthmatic children were taking medication for their condition. However, no 
information for either study was available on the severity of the asthma as measured by lung function (as recommended by an expert panel from the National Heart, Lung and Blood Institute, US Department of Health and Human Services, 2007).

In 2013, the data of both these studies were further explored. The aim was to compare the ten-year-old asthmatic children's need for medication in 1990 to that of ten-year olds in the 2010 study and to examine whether the difference between the two groups is statistically significant. The results are reported here. A sample of three schools in the Vaal Triangle (one each from Sasolburg, Vereeniging and Vanderbijlpark) were randomly selected from the schools that participated in the 1990 VAPS study. Questionnaires from children $(n=271)$ who attended these three schools in 1990 were extracted and compared to data collected during the 2010 study (Mundackal, 2014). The 2010 study population included all 245 ten-year-old children from the sample of the three schools. Both the 1990 and the 2010 studies were designed as a cross-sectional study, thus giving a snap-shot in time of the respiratory health status of the children. Questionnaires completed by the parents of the children were used to characterise the respiratory health status and risk profiles of the participating schoolchildren.

Questions focused on demographics, socioeconomic status, crowding, housing characteristics, sources of indoor pollution and respiratory health. Ethical clearance was obtained from the CSIR Research Ethics Committee (REC number: 03/2010). Questionnaire data from both the 1990 and 2010 studies were captured in EpiData by doubleentry. Thereafter the data were transferred to STATA release 10 , after which univariate and multivariate analyses were done. During the univariate analysis, associations between risk factors (variables) and asthma were determined and results reported as Odds Ratios (ORs) together with the $95 \%$ confidence interval $(\mathrm{Cl})$ and the $\mathrm{p}$-value.

An OR of less than 0.80 and greater than 1.20 in tandem with a p-value less than 0.20 were used as initial cut-off points for significance (this ensured that the majority of exposure variables, inclusive of confounders were extracted to the next stage of regression analyses). All statistically significant variables were further considered for multivariate analysis, during which associations were investigated by means of forward and backward stepwise regression. Significance was set as a pvalue of less than or equal to 0.05 . Here, "prevalence" of asthma was determined by a positive answer to the question whether the child has ever been diagnosed with asthma by a doctor. The need for medication to control the condition was determined by a positive answer to the question whether the child was on asthma medication at the time of the study, as information on the frequency and severity of attacks and hospitalisation was not available from the questionnaires.

\section{Results}

The prevalence of asthma as well as that of asthmatic children on medication for both 1990 and 2010 is shown in Table 1 (Appendix A), together with the $p$ values of the differences between the two studies. The difference in prevalence of asthma during the two study-years was statistically significant ( $p$-value < 0.05). The difference in the percentage of children who had ever been diagnosed with asthma and was reportedly on medication in 1990 and 2010 was however, not statistically significant $(p=0.81)$.

Table 1. Prevalence of and treatment for asthma in 10 -year olds from three schools in the Vaal Triangle in 1990 and 2010.

\begin{tabular}{|l|l|l|l|l|}
\hline Year & $\begin{array}{l}\text { \% Asthma } \\
\text { prevalence }\end{array}$ & P-value & $\begin{array}{l}\% \\
\begin{array}{l}\text { Asthmatic } \\
\text { children } \\
\text { on } \\
\text { medication }\end{array}\end{array}$ & \\
\hline 1990 & $\begin{array}{l}12.41 \% \\
(33 / 266)\end{array}$ & \multirow{2}{*}{0.03} & $\begin{array}{l}30.3 \% \\
(10 / 33)\end{array}$ & \multirow{2}{*}{0.81} \\
& $\begin{array}{l}19.26 \% \\
2010\end{array}$ & & $\begin{array}{l}27.6 \% \\
(13 / 47)\end{array}$ & \\
\hline & $(47 / 244)$ & &
\end{tabular}

\section{Discussion}

It is evident from Table 1 that, although the prevalence of doctor-diagnosed asthma increased significantly between the two studies, the need for treatment for the condition in 2010 was not statistically different from that in 1990. This finding is in contrast with a finding in the United Kingdom ( NgMan Kwong et al., 2001). Their study started in 1991 when they determined the prevalence of asthma and the severity of symptoms in children between 8 and 9 years old who attended the same school. Eight years later (1999), the study was repeated at the same school, again including children aged between 8 and 9 years. Concurrent with the current study, they found a statistically significant increase in the prevalence of asthma between the two studies $(10.3 \%$ to $13.0 \% ; p=$ $<0.001)$. However, medication use also increased statistically significant ( $16.9 \%$ to $20.0 \%$; $p=<0.001$ ) although severity did not. A relatively large number of children without asthma symptoms were found to be on medication in the UK study, resulting in them arguing that the results may suggest overtreatment (Ng Man Kwong et. al., 2001), which does not seem to be the case in the Vaal Triangle study. The current study results corroborate the findings of another study conducted in the Vaal Triangle in 2003. In this study, the prevalence of asthma in ten-year olds who were in Grade 5 in 1990 was compared to their asthma status 13 years later when they were young adults of 23 years old. In the 2003 study, $16 \%$ or 29 individuals indicated that they had been diagnosed with asthma at some stage in their lives. In 1990, when they were ten-years old, only $7 \%$ (12) of these individuals had been diagnosed with asthma. The asthma prevalence in the same individuals thus 
increased with age (Oosthuizen, 2004a). However, in $1990,58 \%$ (7/12 individuals) of the ten-years old children diagnosed with asthma were reportedly on medication, while $38 \%$ of asthmatics (11/29) were on medication in 2003 (Oosthuizen, 2004a). Thus, despite the fact that the prevalence of asthma had more than doubled, fewer individuals were on medication to control the condition, thus there is no evidence of overtreatment. In terms of air quality, it should be noted that the areas where the three schools are situated were fully electrified and nearly $100 \%$ of households used electricity as main energy carrier for cooking in both studies. In the 1990 study, the sulphur dioxide $\left(\mathrm{SO}_{2}\right)$ and oxides of nitrogen $\left(\mathrm{NO}_{\mathrm{x}}\right)$ levels recorded at different stations in the area were considered acceptable as they were below the guidelines at the time (Oosthuizen, 2004a). However, a maximum total suspended particulate (TSP) concentration of $284 \mu \mathrm{g} / \mathrm{m}^{3}$ was measured. At the time the South African guideline was $350 \mu \mathrm{g} / \mathrm{m}^{3}$ and the US-EPA standard $260 \mu \mathrm{g} / \mathrm{m}^{3}$ (Oosthuizen, 2004a). In the 2010 study, levels of $\mathrm{SO}_{2}$ and $\mathrm{NO}_{2}$ recorded at different stations were complying with standards but 24-h levels of $\mathrm{PM}_{10}$ were in exceedance of the South African standard of $120 \mu \mathrm{g} / \mathrm{m}^{3}$. A maximum of $230 \mu \mathrm{g} / \mathrm{m}^{3}$ was measured at one station (SAAQIS, 2012).

\section{Conclusion}

We provide data which indicates that, although the prevalence of asthma increased between 1990 and 2010 in ten-year-old children attending the same schools in the Vaal Triangle, a smaller proportion of these asthmatics were on medication in 2010, indicating that the demand for medication to control the condition may not have increased as well. The reasons for these findings could be investigated in follow-up studies.

\section{Acknowledgements}

The school principals, teachers, schoolchildren and parents who participated in the studies are thanked. The reviewers who gave comments on this manuscript are acknowledged for assistance with improving the article into its current form.

\section{References}

Aaron, S. D., Fergusson, D., Dent, R. Chen, Y., Vandemheen, K. L. and Dales, R. E. 2004. Effect of Weight Reduction on Respiratory Function and Airway Reactivity in Obese Women. Chest 125(6):2046-52.

Chinn, S. 2003. Asthma and obesity: where are we now? Thorax 58:1008-10.

Desalu OO, Salami AK, Oluboyo PO. 2009. SelfReported Risk Factors of Asthma in a Nigerian Adult Population. Turkish Thorasic Journal 10:56-62.
Green RJ. 2011. Pediatric Asthma in Southern Africa. The Open Allergy Journal 4: 8-15.

Lalloo UG, Bateman ED, Feldman C, Bardin PG, Plit M, Irusen, EM and O'Brien J. 2000. Guideline for the management of chronic asthma in adults - 2000 update. South African Medical Journal 90(5): 540-52. Lewis S. 1998. ISAAC--a hypothesis generator for asthma? International Study of Asthma and Allergies in Childhood. Lancet 351(9111):1220-1.

Mishra V. 2003. Effect of Indoor Pollution from Biomass Combustion on Prevalence of Asthma in the Elderly. Environmental Health Perspectives 111 (1): 71-77.

Mundackal AJ. A survey of the respiratory health status of 10-year old children exposed to air pollution in the Vaal Triangle Priority Area in 1990 and in 2010 [draft dissertation] University of Pretoria, 2014.

Ng Man Kwong G, Proctor A, Billings C, Duggan R, Das C, Whyte MKB, Powell CVE and Primhak R. 2001. Increasing prevalence of asthma diagnosis and symptoms in children is confined to mild symptoms. Thorax 56:312-314.

National Heart, Lung and Blood Institute. 2007. Expert Panel Report 3: Guidelines for the Diagnosis and Management of Asthma. Available at: https://www.nhlbi.nih.gov/guidelines/asthma/asthgdl n.pdf (accessed January 2014)

Oosthuizen MA, Jinabhai C, Terblanche APS and Becker P. 2004. Prevalence of asthma in a group of young adults who spent their developing years in the Vaal Triangle, South Africa. Annual conference of the National Association for Clean Air (NACA). Indaba Hotel Johannesburg, 4-8 October 2004.

Oosthuizen MA. 2004a. The Respiratory Health Status of Adults Who Spent Their Developing Years in a Polluted Area in South Africa. A Historical Cohort Study. Masters dissertation University of KwaZuluNatal, 2004.

South African Air Quality Information System ( SAAQIS ). 2012 . A v a il a ble at: http://www.saaqis.org.za/ (accessed February 2014).

Terblanche P.1998. Vaal Triangle Air Pollution Health Study: Bibliography, Summary of Key Findings and Recommendations. ISBN 1-874826-89-7.

To T, Stanojevic S, Moores G, Gershon AS, Bateman ED, Cruz AA and Boulet L-P. 2012. Global asthma prevalence in adults: findings from the crosssectional world health survey. BMC (BioMed Central) Public Health 12:204. [Online] Available:

http://www.biomedcentral.com/1471-2458/12/204 (accessed 2 October 2013). 